\title{
Pharmacokinetic Profile of a 2-Month Dose Regimen of Aripiprazole Lauroxil: A Phase I Study and a Population Pharmacokinetic Model
}

\author{
Marjie L. Hard ${ }^{1,4} \cdot$ Richard J. Mills $^{2} \cdot$ Brian M. Sadler ${ }^{3} \cdot$ Angela Y. Wehr $^{1} \cdot$ \\ Peter J. Weiden ${ }^{1} \cdot$ Lisa von Moltke ${ }^{1}$
}

Published online: 8 June 2017

(C) The Author(s) 2017. This article is an open access publication

\begin{abstract}
Background Aripiprazole lauroxil (AL) is a long-acting injectable medication approved for the treatment of schizophrenia. Current AL regimens are $441 \mathrm{mg}, 662 \mathrm{mg}$, and $882 \mathrm{mg}$ administered monthly (every 4 weeks [q4wk]), or $882 \mathrm{mg}$ administered every 6 weeks (q6wk).

Objective We examined the feasibility of a 2-month (every 8 weeks [q8wk]) dosing interval of AL in a phase I openlabel pharmacokinetic study investigating AL $1064 \mathrm{mg}$ administered q8wk for 24 weeks, followed by 20 weeks of safety and pharmacokinetic measurements (ClinicalTrials.gov ID: NCT02320032). Second, a population pharmacokinetic model (referred to as the 2MPopPK model) was generated using data collected from the present trial, as well as data obtained from earlier studies.

Methods The phase I study included patients with schizophrenia or schizoaffective disorder maintained on an oral antipsychotic $(n=140)$ who were assigned to one of three groups: AL $441 \mathrm{mg} \mathrm{q} 4 \mathrm{wk}$, AL $882 \mathrm{mg}$ q6wk, or AL $1064 \mathrm{mg}$ q8wk, with a total of seven, five, or four
\end{abstract}

Electronic supplementary material The online version of this article (doi:10.1007/s40263-017-0447-7) contains supplementary material, which is available to authorized users.

Lisa von Moltke

Lisa.vonMoltke@alkermes.com

1 Alkermes, Inc., 852 Winter Street, Waltham, MA 02451, USA

2 ICON, Marlow, UK

3 ICON, Gaithersburg, MD, USA

4 Present Address: Nuventra Pharma Sciences, Durham, NC, USA injections administered, respectively. No oral aripiprazole lead-in supplementation was administered and patients continued on maintenance oral antipsychotics. Pharmacokinetic samples were collected at various time points during the 24-week study period and the 20-week followup period. Plasma concentrations obtained from the phase I study were analyzed using non-compartmental methods. Additionally, the data were combined with data collected from prior studies to develop the 2MPopPK model.

Results Following the final injection of AL in the phase I study, maximum aripiprazole concentrations were achieved 24.4-35.2 days after the last dose and persisted for the duration of the study. The mean $C_{\mathrm{avg}, \mathrm{ss}}$ values were $125.8 \mathrm{ng} / \mathrm{ml}, 131.1 \mathrm{ng} / \mathrm{ml}$, and $140.7 \mathrm{ng} / \mathrm{ml}$ for the $441 \mathrm{mg}$ q4wk, $882 \mathrm{mg}$ q6wk, and $1064 \mathrm{mg}$ q8wk doses, respectively. The mean elimination half-life of aripiprazole following the last dose was 53.9 days for the $1064 \mathrm{mg}$ dose, 55.1 days for the $882 \mathrm{mg}$ dose, and 57.2 days for the $441 \mathrm{mg}$ dose. The 2MPopPK dataset included 14,524 aripiprazole concentrations from 700 patients with schizophrenia. The duration of absorption of aripiprazole was estimated as 43 days (95\% confidence interval [CI] 42-45 days), which was preceded by a 3.2-day lag time (95\% CI 3.0-3.5 days) for a total duration of input into the systemic circulation of 46 days following intramuscular administration of AL. Multiple-dose simulations showed that the $1064 \mathrm{mg}$ q8wk regimen provides aripiprazole concentrations within the concentration range associated with $441 \mathrm{mg}$ and $882 \mathrm{mg} \mathrm{q} 4 \mathrm{wk}$ doses previously demonstrated to be efficacious in a phase III study.

Conclusion These data from the phase I study and the 2MPopPK model support the suitability of using the AL $1064 \mathrm{mg}$ dose as a 2-month (q8wk) dose interval option for the treatment of schizophrenia. 


\section{Key Points}

Based on the 2MPopPK model, the $1064 \mathrm{mg}$ every 8 weeks (q8wk) regimen of aripiprazole lauroxil provides concentrations within the range of approved monthly (every 4 weeks [q4wk]) doses (441 and $882 \mathrm{mg}$ ).

The mean elimination half-life of aripiprazole following the last dose ranged from 53.9 to 57.2 days, across the dose range of 441-1064 mg.

The pharmacokinetic characteristics of aripiprazole lauroxil include a duration of absorption of 46 days, allowing the extension of the dosing interval to 2 months (q8wk).

\section{Introduction}

Schizophrenia often requires long-term maintenance antipsychotic treatment to prevent relapse and recurrence [1]. Antipsychotic withdrawal can occur in a variety of circumstances, and even relatively brief interruptions or disruptions of medication continuity are associated with exacerbation of symptoms and an increased risk of relapse and hospitalization [2-4].

Antipsychotics are available as oral medications that need to be taken daily or as long-acting injectable formulations given at intervals ranging from every 2 weeks to every 3 months, depending on the specific long-acting agent. Aripiprazole lauroxil (AL) is an intramuscular injectable extended-release prodrug of aripiprazole that is approved for the treatment of schizophrenia [5, 6]. Pivotal clinical studies have demonstrated that AL $441 \mathrm{mg}$ and $882 \mathrm{mg}$ doses administered monthly (every 4 weeks [q4wk]) are efficacious $[7,8]$ and population pharmacokinetic (PopPK) modeling provided the pharmacokinetic basis for the approval of the $662 \mathrm{mg}$ dose $\mathrm{q} 4 \mathrm{wk}$ and the $882 \mathrm{mg}$ dose every 6 weeks (q6wk) [9].

We hypothesized that extending the $\mathrm{AL}$ regimens to include a dose that could support a 2-month (every 8 weeks [q8wk]) dose interval may offer additional medication regimen options. Here, we report the results from a phase I study (A105) in which AL $1064 \mathrm{mg}$ was administered q8wk over the course of 24 weeks. Extensive pharmacokinetic sampling was performed during the period of $\mathrm{AL}$ administration and for an additional 20 weeks following the last dose. A PopPK analysis was conducted using these data and previously collected AL pharmacokinetic data to further evaluate the pharmacokinetics of an $\mathrm{AL} 1064 \mathrm{mg}$ dose q8wk (2MPopPK model).

\section{Methods}

\subsection{Phase I Pharmacokinetic Study}

The phase I open-label study (A105, ClinicalTrials.gov ID: NCT02320032) was conducted at 15 clinical sites in the USA between December 2014 and April 2016 and evaluated the pharmacokinetics, safety, and tolerability of the $1064 \mathrm{mg}$ q8wk regimen (two formulations with different particle sizes were included, $\mathrm{S}$ formulation was not pursued for further clinical development), along with two approved AL dose interval regimens (441 $\mathrm{mg} \mathrm{q} 4 \mathrm{wk}$ and $882 \mathrm{mg}$ q6wk). Patients were clinically stable adults with schizophrenia or schizoaffective disorder (Diagnostic and Statistical Manual of Mental Disorders, Fifth edition [DSM-V]) who were already stabilized on an oral antipsychotic other than aripiprazole. To isolate the pharmacokinetics of the intramuscular injections for the AL regimens, no oral aripiprazole initiation was given, and most patients continued on the same oral antipsychotic as per clinical recommendation of the investigator (see Supplemental Table 1 in the Electronic Supplementary Material [ESM] for more details, including full inclusion and exclusion criteria for the phase I study). The protocol allowed for administration of oral aripiprazole prior to randomization to ensure tolerability for patients without prior experience with aripiprazole. The study was reviewed and approved by an institutional review board and conducted in accordance with the ethical principles that have their origins in the Declaration of Helsinki (1964), Good Clinical Practice Guidelines issued by the International Council for Harmonisation of Technical Requirements for Registration of Pharmaceuticals for Human Use, Federal Code of Regulations Title 21, and other applicable international and local laws and regulations. All patients provided informed written consent before entering the study.

Patients who successfully completed the screening period were assigned to one of three groups: $441 \mathrm{mg} \mathrm{q} 4 \mathrm{wk}, 882 \mathrm{mg}$ q6wk, or $1064 \mathrm{mg} \mathrm{q8wk}$, all administered by intramuscular gluteal injection. Patients were seen every 2 weeks for safety assessments and pharmacokinetic sampling but received their respective AL regimen at different scheduled intervals over the 24-week period, corresponding to a total of four, five, or seven injections of $1064 \mathrm{mg}, 882 \mathrm{mg}$, or $441 \mathrm{mg}$, respectively. The last dose for all AL regimens was administered at the end of the 24th week, on Day 169. Patients returned to the clinic for additional study assessments, procedures, and continued pharmacokinetic sampling for 20 weeks after the last injection. Safety data from the phase I study will be reported in a separate publication [10].

Plasma concentrations and concentration-time data were evaluated for aripiprazole at regular intervals, with a maximum of 48 samples per patient taken over 309 days. 
Pharmacokinetic parameters were calculated by non-compartmental analysis, using actual elapsed time from dosing to estimate individual plasma pharmacokinetic parameters. Calculated pharmacokinetic parameters included maximum plasma concentration $\left(C_{\max }\right)$, average steady-state plasma concentration during multiple-dose administration $\left(C_{\mathrm{avg}, \mathrm{ss}}\right)$, half-life $\left(t_{1 / 2}\right)$, and area under the curve (AUC) over the dose interval (AUC). $C_{\mathrm{avg}, \mathrm{ss}}$ was calculated as $\mathrm{AUC}_{\tau \mathrm{ss} / \tau}$, where $\mathrm{AUC}_{\mathrm{ss}}$ is the AUC of concentration versus time after a steady-state dose, and $\tau$ is the dosing interval.

\subsection{Two-Month Population Pharmacokinetic Model}

The 2MPopPK model presented here was informed by the observed pharmacokinetic data from the phase I study (A105) and the previous PopPK model [11]. In addition to this current phase I pharmacokinetic study, the dataset for the $2 \mathrm{MPopPK}$ model used four other studies that had also been included in the previous PopPK model [11]. These include three prior pharmacokinetic studies $(002,101,102)$ and pharmacokinetic data from the pivotal efficacy study (003) (Table 2 in the ESM). Data from one study included in the earlier PopPK model (001) was not included in the 2MPopPK model because a non-commercial formulation of study drug was administered. A total of 14,524 (including 826 [6\%] <lower limit of quantification [LLOQ]) aripiprazole concentrations from 700 patients were included in the analysis. The phase I (A105) study contributed 5077 (including 90 [2\%] <LLOQ) aripiprazole concentrations from 124 patients to this analysis, whereas the prior studies provided data from 576 patients.

The model was developed using non-linear mixed effect modeling, with NONMEM ${ }^{\circledR}$ program version 7.3.0. PDxPop version 5.1 used as the NONMEM interface. As described in the ESM, modeling proceeded first by developing a base model for which the goodness of fit was assessed by a variety of plots and computed metrics, including plots of population and individual predictions versus observations and versus time, plots of conditional/ individual weighted residuals versus predictions and versus time, histograms and quartile-quartile plots of conditional/ individual weighted residuals and of the $\eta$, scatter plots of $\eta$ pairs and $\eta$ versus modeled covariates, and plots overlaying observed and predicted values versus time. The effect of both continuous (dose, age, body weight) and categorical covariates (race, ethnicity, sex, particle size of the $1064 \mathrm{mg}$ dose, cytochrome P450 [CYP]-2D6 phenotype, route of administration, dose regimen) were then assessed using a backward deletion approach. All relevant covariates were added to the model (the full model), and the backward deletion was performed to assess the relative influence of each covariate on the model by deleting it from the full model on an individual basis until a final model was identified. The final model was assessed by applying a posterior visual predictive check and by calculating the percentage of the observations outside the $90 \%$ prediction intervals.

As this phase I study did not include data from oral aripiprazole co-administration, the parameters for oral administration in the $2 \mathrm{MPopPK}$ model were derived from estimates from the earlier PopPK model [11]. CYP2D6 polymorphisms were evaluated as described previously [11]. Consistent with the earlier PopPK model, the covariate effects of central volume of distribution $(\mathrm{VC} / \mathrm{F})$ increasing with weight (fixed at an allometric scaling value of 1.0) and lower apparent clearance (CL/F) in CYP2D6 poor metabolizers were retained (Sect. 5 in the ESM). The earlier PopPK model included aripiprazole and dehydroaripiprazole, whereas the $2 \mathrm{MPopPK}$ model was developed for aripiprazole only to ensure stability and allow for formal statistical evaluation of covariates (see Description of the Base Model in the ESM). Therefore, the 2MPopPK model contained only aripiprazole central and peripheral compartments and associated parameters (the structure of the 2MPopPK model is illustrated in Fig. 1 in the ESM). The previous PopPK model contained four intramuscular dosing compartments, one oral aripiprazole dosing compartment, and one central and one peripheral compartment each for aripiprazole and dehydro-aripiprazole [11]. The present 2MPopPK model contained seven intramuscular dosing compartments representing the maximum number of $\mathrm{AL}$ doses administered, one oral aripiprazole dosing compartment, one central compartment, and one peripheral compartment for aripiprazole only.

Using the 2MPopPK model, simulations were performed to predict aripiprazole concentration-time profiles after repeated administration of AL at doses of $1064 \mathrm{mg}$ q8wk, relative to the approved AL regimens of $441 \mathrm{mg}$, $662 \mathrm{mg}$, and $882 \mathrm{mg} \mathrm{q} 4 \mathrm{wk}$, and $882 \mathrm{mg} \mathrm{q6wk}$, including daily supplementation with oral aripiprazole $15 \mathrm{mg}$ for 21 days with the first injection. Aripiprazole-equivalent doses of $300 \mathrm{mg}, 450 \mathrm{mg}, 600 \mathrm{mg}$, and $724 \mathrm{mg}$ were used for modeling and simulation, which correspond to $441 \mathrm{mg}$, $662 \mathrm{mg}, 882 \mathrm{mg}$, and $1064 \mathrm{mg}$ of AL, respectively. For each set of Monte-Carlo simulations, 500 individual aripiprazole concentration-time profiles were generated.

\section{Results}

\subsection{Phase I Pharmacokinetics}

Of 140 patients randomized in the phase I study, 104 were included in the pharmacokinetic population. One patient enrolled in the $882 \mathrm{mg}$ group withdrew consent on Day 1 and did not receive the study drug. The AL 1064 (S) mg 
formulation was not developed further, and therefore the 35 patients who received this formulation are not included in the analysis. Pharmacokinetic parameters were not reportable for some subjects due to either early termination $(n=22)$ or sample error $(n=3)$. The mean patient age was $44.5 \pm$ standard deviation (SD) 11.4 years; $73 \%$ were male, $75 \%$ were Black/African American, and mean \pm SD body weight and body mass index were $89.8 \pm 16.9$ and $29.3 \pm 4.5 \mathrm{~kg}$, respectively (Table 1). Patient demographics were comparable across the treatment groups in the phase I study. Generally, safety of all doses evaluated in the phase I study was consistent with previous reports [7] and is detailed in a separate publication [12].

Following the final injection of AL in the phase I study, maximum aripiprazole concentrations were achieved 24.4-35.2 days after the last dose and persisted for the duration of the study (Fig. 1). The mean $C_{\mathrm{avg}, \mathrm{ss}}$ values are presented in Table 2. The mean elimination half-life of aripiprazole following the last dose ranged from 53.9 to 57.2 days for all three dose groups (Table 2).

\subsection{Two-Month Population Pharmacokinetic Model of Aripiprazole Lauroxil}

Observed versus predicted aripiprazole concentrations for the $1064 \mathrm{mg}$ q8wk regimen were evaluated using the model; simulations showed that more than $90 \%$ of observed aripiprazole concentrations were within the 5 th and 95th percentiles of therapeutic concentration range estimated for AL. The duration of absorption of aripiprazole was estimated to be 43 days ( $95 \%$ confidence interval [CI] 42-45), and the lag time for the appearance of aripiprazole in the central compartment was 3.2 days $(95 \%$ CI
3.0-3.5), suggesting that the total length of time that aripiprazole continues to enter the systemic circulation following a single injection is 46 days.

A total of seven covariates were included in a full covariate model, including two covariates that were previously included in the PopPK model (weight on $\mathrm{VC}$ / $\mathrm{F}$ and CYP2D6 poor metabolizer status on CL/F) [11]. Of the five additional covariates analyzed (surface area on bioavailability following intramuscular administration [FIM], absorption lag time [ALAG] and input duration [D1], race and sex on CL/F), two did not have any effect (Table 3 in the ESM). These were an estimated $25 \%$ decrease in ALAG for the formulation with lower surface area and a $16 \%$ decrease in $\mathrm{CL} / \mathrm{F}$ for females in comparison with males. The effect of race on $\mathrm{CL} / \mathrm{F}$ and surface area on both D1 and FIM included 1.0 in the $95 \%$ CI values. The inclusion of race and sex as covariates did not result in a decrease in objective function value (OFV) and thus were not retained in the model. The final model contained the covariate effect for $\mathrm{VC} / \mathrm{F}$ to increase with weight and the reduction in $\mathrm{CL} / \mathrm{F}$ for CYP2D6 poor metabolizers (see additional details in the ESM [Sect. 5]).

\subsection{Model Simulations}

The 2MPopPK model was used to simulate aripiprazole concentration-time profiles after administration of AL in multiple-dosing regimens. The simulated pharmacokinetic parameters for AL $441 \mathrm{mg} \mathrm{q} 4 \mathrm{wk}, 662 \mathrm{mg} \mathrm{q} 4 \mathrm{wk}, 882 \mathrm{mg}$ q4wk, and $882 \mathrm{mg}$ q6wk (Table 4 in the ESM) were consistent with simulated values from the prior PopPK model [11].

Table 1 Demographic and baseline characteristics of the safety population in the phase I study

\begin{tabular}{lllll}
\hline Category & $441 \mathrm{mg}(n=35)$ & $882 \mathrm{mg}(n=34)$ & $1064 \mathrm{mg}(n=35)$ & $1064(\mathrm{~S}) \mathrm{mg}^{\mathrm{a}}(n=35)$ \\
\hline Age, years & $46.3 \pm 11.0$ & $44.8 \pm 12.4$ & $44.9 \pm 10.7$ & $42.1 \pm 11.5$ \\
Male sex & $20(57.1)$ & $25(73.5)$ & $29(82.9)$ & $28(80.0)$ \\
Ethnicity & & & $31(88.6)$ & $35(100.0)$ \\
$\quad$ Not Hispanic or Latino & $34(97.1)$ & $32(94.1)$ & $4(11.4)$ & 0 \\
$\quad$ Hispanic or Latino & $1(2.9)$ & $2(5.9)$ & & $27(77.1)$ \\
Race & & & $26(74.3)$ & $8(22.9)$ \\
Black or African American & $26(74.3)$ & $25(73.5)$ & $9(25.7)$ & 0 \\
White & $9(25.7)$ & $8(23.5)$ & 0 & $90.1 \pm 18.0$ \\
$\quad$ Other & 0 & $1(2.9)$ & $88.52 \pm 18.3$ & $29.3 \pm 4.4$ \\
Weight, kg & $92.5 \pm 16.4$ & $88.6 \pm 15.9$ & $29.3 \pm 4.4$ & \\
Body mass index, $\mathrm{kg} / \mathrm{m}^{2}$ & $30.3 \pm 4.3$ & 29.3 & \\
\hline
\end{tabular}

Data are presented as $n(\%)$ or mean \pm standard deviation

${ }^{a}$ The $\mathrm{S}$ formulation of aripiprazole lauroxil is not being developed further; data from this cohort are not presented in this manuscript 
Fig. 1 Mean (standard deviation) aripiprazole plasma concentrations in the phase I study following multiple doses of aripiprazole lauroxil administered using three dosing regimens. All aripiprazole lauroxil regimens in the clinical study were administered on Day 169. All patients were followed for 20 weeks for continued safety and pharmacokinetics assessment. $A L$ aripiprazole lauroxil, $q X w k$ every $\mathrm{X}$ weeks

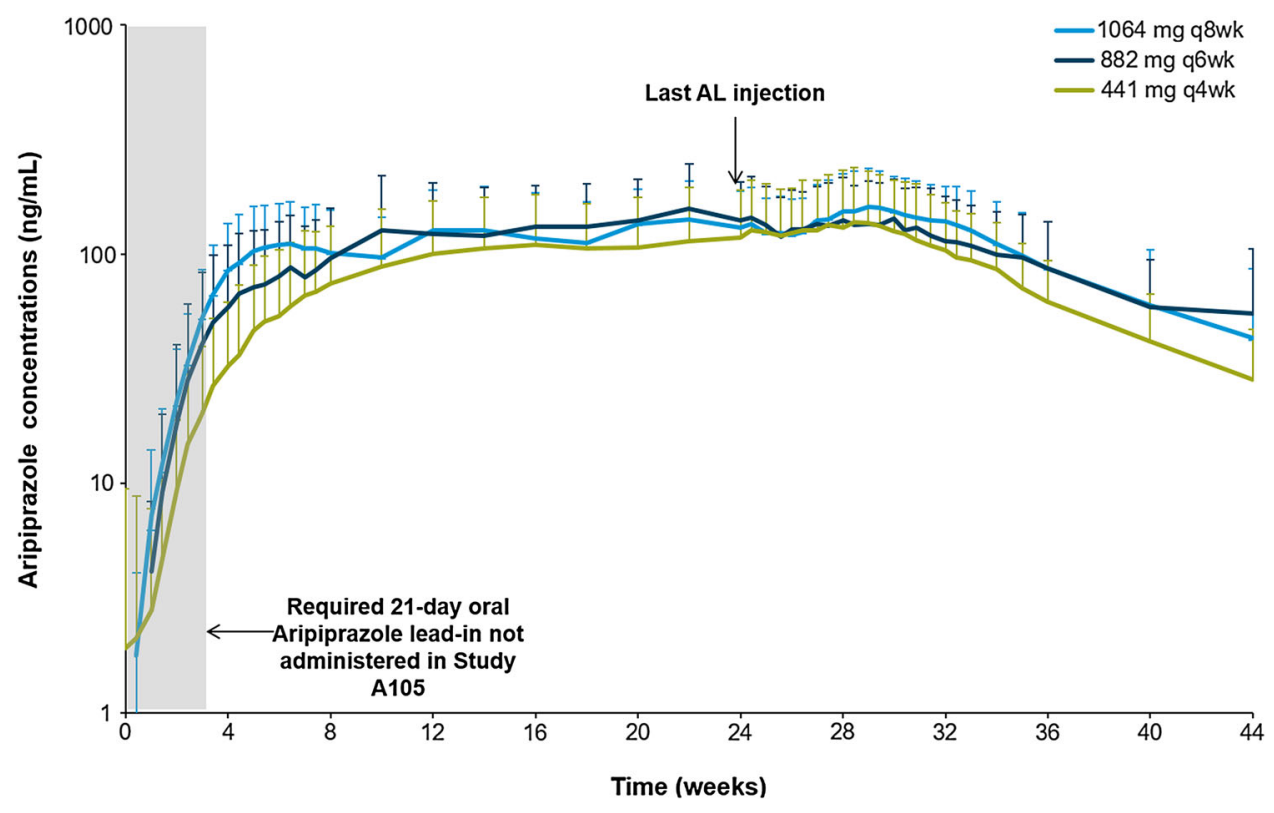

Table 2 Pharmacokinetic parameters of aripiprazole determined in the phase I study following last dose by treatment group

\begin{tabular}{|c|c|c|c|}
\hline \multirow[t]{2}{*}{ Parameter $^{\mathrm{a}}$} & \multicolumn{3}{|l|}{ Mean $(\% \mathrm{CV})$} \\
\hline & $441 \mathrm{mg} \mathrm{q} 4 \mathrm{wk}(n=28)$ & $882 \mathrm{mg} \mathrm{q} 6 \mathrm{wk}(n=23)$ & $1064 \mathrm{mg} \mathrm{q} 8 \mathrm{wk}(n=28)$ \\
\hline$C_{\max }, \mathrm{ng} / \mathrm{ml}$ & $161(67.8)$ & $172(47.3)$ & $189(42.3)$ \\
\hline$C_{\text {avg,ss }}, \mathrm{ng} / \mathrm{ml}$ & $126(63.3)$ & $131(47.4)$ & $141(40.7)$ \\
\hline $\mathrm{AUC}_{\tau}$, day $\times \mathrm{ng} / \mathrm{ml}$ & $3520(63.3)$ & $5510(47.4)$ & $7880(40.7)$ \\
\hline$t_{1 / 2}$, days & $57.2(75.2)^{\mathrm{b}}$ & $55.1(58.0)^{\mathrm{c}}$ & $53.9(77.9)^{\mathrm{d}}$ \\
\hline
\end{tabular}

$\% C V$ percent coefficient of variation, $A U C_{\tau}$ area under the curve over the dosing interval, $C_{a v g, s s}$ average concentration at steady state, $C_{\text {max }}$ maximum plasma concentration, $q X w k$ every $X$ weeks, $t_{1 / 2}$ half-life

${ }^{a}$ Data from the phase I study, arithmetic means reported. Duration of sampling, 140 days; number of sampling days, 24 days; samples collected after Day 28, 15. Pharmacokinetic parameters were not reportable for some subjects due to either early termination $(n=22)$ or sample error $(n=3)$

b $n=22$

${ }^{\text {c }} n=19$

${ }^{\mathrm{d}} n=26$

In the 2MPopPK model, we performed multiple-dose simulations with 21 days of oral aripiprazole $15 \mathrm{mg}$ coadministered with the first $1064 \mathrm{mg}$ dose of AL (1064 mg q8wk) over 56 weeks and evaluated median aripiprazole concentrations relative to the efficacious doses established in the phase III pivotal study [7]. The repeated-dose simulations showed that a $1064 \mathrm{mg}$ q8wk regimen achieved aripiprazole concentrations within the concentration range predicted for the $441 \mathrm{mg}$ and $882 \mathrm{mg}$ q4wk regimens (Fig. 2a). Simulated median aripiprazole concentrations for AL $441 \mathrm{mg}, 662 \mathrm{mg}$, and $882 \mathrm{mg} \mathrm{q} 4 \mathrm{wk}$ and AL $441 \mathrm{mg}$ q4wk, $882 \mathrm{mg}$ q4wk, and $882 \mathrm{mg}$ q6wk are shown in Fig. 2b, c, respectively. The $C_{\mathrm{avg}, \mathrm{ss}}$ for the $1064 \mathrm{mg} \mathrm{q} 8 \mathrm{wk}$ regimen was within the $441 \mathrm{mg} \mathrm{q} 4 \mathrm{wk}$ and $882 \mathrm{mg}$ q6wk dose ranges (Fig. 3; Table 4 in the ESM).

\section{Discussion}

The results of the phase I study and subsequent 2MPopPK model-based evaluations presented here demonstrated that the $1064 \mathrm{mg}$ q8wk regimen provided aripiprazole concentrations within the concentration range associated with $441 \mathrm{mg}$ and $882 \mathrm{mg} \mathrm{q} 4 \mathrm{wk}$ regimens that were previously determined to be efficacious in a phase III study [7, 9].

Data from the phase I pharmacokinetic study of $1064 \mathrm{mg}$ were included in the 2MPopPK model, which was developed using the previously described PopPK model, published elsewhere, and included data from three prior phase I studies as well as a phase III study [11]. One limitation of the phase I study is that it did not include leadin oral aripiprazole supplementation, which is necessary for 

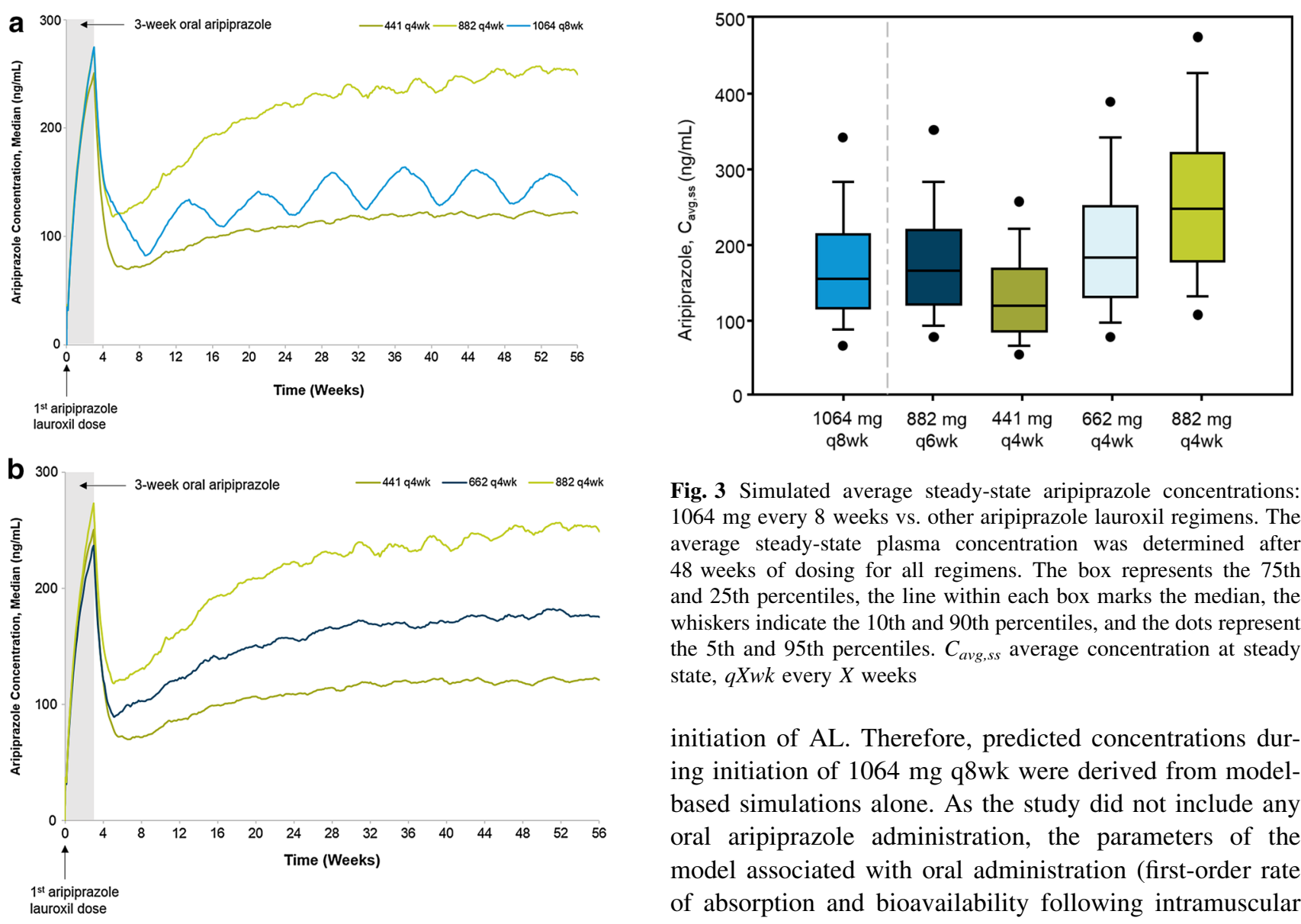

Fig. 3 Simulated average steady-state aripiprazole concentrations: $1064 \mathrm{mg}$ every 8 weeks vs. other aripiprazole lauroxil regimens. The average steady-state plasma concentration was determined after 48 weeks of dosing for all regimens. The box represents the 75 th and 25th percentiles, the line within each box marks the median, the whiskers indicate the 10th and 90th percentiles, and the dots represent the 5 th and 95 th percentiles. $C_{a v g, s s}$ average concentration at steady state, $q X w k$ every $X$ weeks

initiation of AL. Therefore, predicted concentrations during initiation of $1064 \mathrm{mg}$ q8wk were derived from modelbased simulations alone. As the study did not include any oral aripiprazole administration, the parameters of the model associated with oral administration (first-order rate of absorption and bioavailability following intramuscular administration) were fixed to the estimates obtained from the earlier PopPK model.

The mean elimination half-life of aripiprazole following the last dose ranged from 53.9 to 57.2 days, which is longer than previously reported (29.2-34.9 days) [6]. The difference is attributed to the fact that, compared with previous studies, the phase I study had a longer duration and higher density of pharmacokinetic sampling during the elimination phase, which was characterized 20 weeks after the last AL dose, and therefore provides a more accurate estimate of the half-life.

Like other long-acting injectables [13], AL has a slow dissolution after injection [9] and therefore exhibits flipflop kinetics determined by an absorption rate that is slower than the elimination rate, resulting in an extended pharmacokinetic profile. Thus, the calculated half-life using the non-compartmental analysis is substantially greater than that for oral aripiprazole and is influenced by the flip-flop kinetics.

Consistent with the slow dissolution of AL that governs the release of drug, the 2MPopPK model characterized the uptake of aripiprazole after AL administration as having a 3.2-day lag time and a 43-day duration of absorption for a the daily oral aripiprazole $15 \mathrm{mg}$ supplementation. $q X w k$ every $X$ weeks

Fig. 2 Simulated median aripiprazole concentration for initiation of aripiprazole lauroxil with oral aripiprazole $15 \mathrm{mg}$ for 21 days: a $1064 \mathrm{mg}$ every 8 weeks vs. lowest and highest approved aripiprazole lauroxil doses. b $441 \mathrm{mg}$ every 4 weeks vs. $662 \mathrm{mg}$ every 4 weeks and $882 \mathrm{mg}$ every 4 weeks. c $441 \mathrm{mg}$ every 4 weeks vs. $882 \mathrm{mg}$ every 4 weeks and $882 \mathrm{mg}$ every 6 weeks. The aripiprazole concentrations between Weeks 0 and 3 reflect combined concentrations from the first aripiprazole lauroxil injection and from 
total duration of input into the systemic circulation of 46 days. As previously reported, AL is rapidly converted to the active metabolite with no measurable concentrations of the prodrug detected [9]. Thus, it is unlikely that the conversion rate or the volume of distribution of $\mathrm{AL}$ is responsible for the slow elimination of aripiprazole. These results suggest that aripiprazole concentrations increase throughout the majority of the dosing interval, explaining the ability to extend the dosing interval to q8wk.

Overall, the model parameter estimates, covariate effects, and simulated exposures are consistent with the previously presented PopPK model [11]. Polymorphisms of xenobiotic-metabolizing enzymes, particularly CYP2D6 status, can produce variability in aripiprazole and dehydroaripiprazole exposure. Of 700 patients in the analysis, 25 were poor metabolizers. While the CYP2D6 covariate was retained in the model (Sect. 5 of the ESM), the overall predictions do not suggest a clinically meaningful difference in exposure to aripiprazole, and consequently dehydro-aripiprazole, in CYP2D6 poor metabolizer patients. The studies included in the 2MPopPK analysis did not include patients who were ultra-rapid CYP2D6 metabolizers; thus, no conclusions can be made for this phenotype. No other formulation of aripiprazole provides guidance for this CYP2D6 phenotype.

In general, extended dosing intervals could potentially reduce the number of clinic visits, when clinically appropriate, and therefore may reduce the overall treatment burden. Additionally, more dosing options may allow clinicians to select the appropriate doses and dose intervals to fulfill the treatment needs of each patient, and may facilitate patient-oriented decision making.

\section{Conclusion}

Results from the phase I study and the 2MPopPK model demonstrate that the AL $1064 \mathrm{mg}$ q8wk dose regimen provides plasma concentrations of aripiprazole that are within the ranges of the approved AL doses (441 and $882 \mathrm{mg}$ ). These findings support the suitability of $1064 \mathrm{mg}$ $\mathrm{AL}$ as a regimen for the treatment of schizophrenia that is given every 2 months (q8wk).

Acknowledgements The authors would like to acknowledge editorial assistance from Nicole Seneca, AlphaBioCom, LLC, USA, and Mia Cahill, ApotheCom, UK, in revising and editing the manuscript. This assistance was funded by Alkermes Inc., Waltham, MA, USA. Journal open-access costs were also met by Alkermes, Inc.

Authors' Contributions MLH, RJM, BMS, AW, and LvM contributed to the study design, statistical and bioanalytic analysis, PopPK model development, and running simulations. All authors contributed to results interpretation and the drafting of the manuscript.
All authors reviewed and approved the manuscript prior to submission.

\section{Compliance with Ethical Standards}

Conflicts of interest Dr Hard is a former employee of Alkermes and is presently an employee of Nuventra Pharma Sciences. Drs Wehr, Weiden, and von Moltke are employees of Alkermes. Drs Sadler and Mills are employees of ICON plc and contracted by Alkermes to perform the work described in this manuscript.

Funding This study was sponsored by Alkermes Inc.

Ethical approval All procedures performed in studies involving human participants were in accordance with the ethical standards of the institutional and/or national research committee and with the 1964 Helsinki declaration and its later amendments or comparable ethical standards.

Informed consent Informed consent was obtained from all individual participants included in the study.

Open Access This article is distributed under the terms of the Creative Commons Attribution-NonCommercial 4.0 International License (http://creativecommons.org/licenses/by-nc/4.0/), which permits any noncommercial use, distribution, and reproduction in any medium, provided you give appropriate credit to the original author(s) and the source, provide a link to the Creative Commons license, and indicate if changes were made.

\section{References}

1. Robinson D, Woerner MG, Alvir JM, Bilder R, Goldman R, Geisler $\mathrm{S}$, et al. Predictors of relapse following response from a first episode of schizophrenia or schizoaffective disorder. Arch Gen Psychiatry. 1999;56(3):241-7.

2. Lindenmayer JP, Liu-Seifert H, Kulkarni PM, Kinon BJ, Stauffer $\mathrm{V}$, Edwards SE, et al. Medication nonadherence and treatment outcome in patients with schizophrenia or schizoaffective disorder with suboptimal prior response. J Clin Psychiatry. 2009;70(7):990-6.

3. Weiden PJ, Kozma C, Grogg A, Locklear J. Partial compliance and risk of rehospitalization among California Medicaid patients with schizophrenia. Psychiatr Serv. 2004;55(8):886-91.

4. Tiihonen J, Haukka J, Taylor M, Haddad PM, Patel MX, Korhonen P. A nationwide cohort study of oral and depot antipsychotics after first hospitalization for schizophrenia. Am J Psychiatry. 2011;168(6):603-9.

5. Alkermes Inc. Aristada (Aripiprazole Lauroxil) Prescribing Information. 2017. https://www.aristadahcp.com/downloadables/ ARISTADA-PI.pdf. Accessed May 2017.

6. Cruz MP. Aripiprazole lauroxil (Aristada): an extended-release, long-acting injection for the treatment of schizophrenia. P T. 2016;41(9):556-9.

7. Meltzer HY, Risinger R, Nasrallah HA, Du Y, Zummo J, Corey $\mathrm{L}$, et al. A randomized, double-blind, placebo-controlled trial of aripiprazole lauroxil in acute exacerbation of schizophrenia. J Clin Psychiatry. 2015;76(8):1085-90.

8. Potkin SG, Risinger R, Du Y, Zummo J, Bose A, Silverman B, et al. Efficacy and safety of aripiprazole lauroxil in schizophrenic patients presenting with severe psychotic symptoms during an acute exacerbation. Schizophr Res. 2017. doi:10.1016/j.schres. 2017.03.003 (Epub 22 Mar 2017). 
9. Turncliff R, Hard M, Du Y, Risinger R, Ehrich EW. Relative bioavailability and safety of aripiprazole lauroxil, a novel oncemonthly, long-acting injectable atypical antipsychotic, following deltoid and gluteal administration in adult subjects with schizophrenia. Schizophr Res. 2014;159(2-3):404-10.

10. Risinger R, Hard M, Weiden PJ. A phase 1 study comparing pharmacokinetic and safety profiles of three different dose intervals of aripiprazole lauroxil. San Diego: American Psychiatric Association Annual Meeting; 2017.

11. Hard ML, Mills RJ, Sadler BM, Turncliff RZ, Citrome L. Aripiprazole lauroxil: pharmacokinetic profile of this long-acting injectable antipsychotic in persons with schizophrenia. J Clin Psychopharmacol. 2017;37(3):289-95.

12. Weiden PJ, Hard ML, Risinger R, Yangchun D, Walling DP, Marandi M. Safety and tolerability of 4, 6, and 8 week dose intervals of long-acting aripiprazole lauroxil. Miami: American Society of Clinical Psychopharmacology Annual Meeting; 2017.

13. Spanarello S, La Ferla T. The pharmacokinetics of long-acting antipsychotic medications. Curr Clin Pharmacol. 2014;9(3):310-7. 